\title{
PENGARUH PERLAKUAN TEMPERATUR DAN MEDIA PENDINGINAN TERHADAP SIFAT KETANGGUHAN BAJA AISI 3215
}

\author{
K Suarsana $^{1)^{\star}}$, IGN Nitya Santhiarsa ${ }^{2)}$, DNK Putra Negara ${ }^{3)}$ \\ ${ }^{1)}$ Teknik Mesin Fakultas Teknik Universitas Udayana \\ Kampus Bukit Jimbaran Bali 80362 \\ Email : ktsuarsana@yahoo.com / suarsana@unud.ac.id \\ ${ }^{2)}$ Teknik Mesin Fakultas Teknik Universitas Udayana \\ Kampus Bukit Jimbaran, Bali 80362 \\ Email : santhiarsa@yahoo.com \\ ${ }^{3)}$ Teknik Mesin Fakultas Teknik, Universitas Udayana \\ Kampus Bukit Jimbaran, Bali 80362
}

doi: https://doi.org/10.24843/METTEK.2018.v04.i01.p04

\begin{abstract}
Abstrak
Perlakuan panas adalah pemanasan yang diikuti dengan penahanan dan pendinginan menggunakan media quenching. Pengerasan adalah pemanasan logam hingga suhu austenit, tahan pada suhu tersebut untuk sementara waktu dan kemudian didinginkan pada media pendinginan seperti air, minyak, udara, air garam. Untuk mengatasi perubahan sifat mekanik, perlu diberikan proses perlakuan panas. Hal ini perlu dilakukan untuk menghilangkan stress internal dan mencegah terjadinya retak atau cacat. Sifat mekanis ketangguhan adalah kemampuan material untuk menyerap energi sesaat sebelum terjadi fraktur pada struktur itu. Penelitian ini membahas tentang prediksi ketangguhan properti mekanik dengan memberikan pemanasan pada temperatur 800 , 850 dan $900^{\circ} \mathrm{C}$ dan masing-masing specimen diquenching dengan : air tawar, air laut dan minyak. Hasil penelitian menunjukkan bahwa terjadi peningkatan sifat ketangguhan dari efek temperatur dan media pendinginan yang digunakan. Data menunjukan pada $800^{\circ} \mathrm{C}$ dengan media quenching minyak nilai ketangguhan adalah $33,833 \mathrm{~kg} / \mathrm{cm}^{2}$, serta suhu $900^{\circ} \mathrm{C}$ dengan quenching media air nilai ketangguhan adalah $40,8747 \mathrm{~kg} / \mathrm{cm}^{2}$ ). Jadi semakin meningkat temperature perlakuan, berpengaruh terhadap sifat ketangguhan impak bahan.
\end{abstract}

Kata kunci : Perlakuan panas, Quenching, Ketangguhan

\begin{abstract}
Heat treatment is carried out by heating followed by anchoring and using quenching medium as cooling. Hardening is metal heating to austenite temperature, hold it at a temporary temperature and then cooled to cooling media such as water, oil, air, brine. To overcome the change of mechanical properties, need to be given the process of heat treatment. This is to remove internal stress and prevent the occurrence of cracks or defects. The mechanical properties of toughness are the ability of the material to absorb energy without fracturing the structure. This study discusses the prediction of toughness of mechanical properties by heating at temperatures of 800,850 and 9000C and each specimen quenching with: freshwater, seawater, and oil. The results showed that there was an increase in the toughness properties of the temperature effect and the cooling medium used. The data show on $8000 \mathrm{C}$ with medium quenching oil the toughness value is $33.833 \mathrm{~kg} / \mathrm{cm} 2$, and the temperature of $9000 \mathrm{C}$ with quenching medium water toughness value is $40.8747 \mathrm{~kg} / \mathrm{cm} 2$ ). So the increase of treatment temperature has the influence on the material toughness.
\end{abstract}

\footnotetext{
${ }^{*}$ Penulis korespodensi

Email: ktsuarsana@yahoo.com / suarsana@unud.ac.id
} 
Keywords: heat treatment, quenching, toughness.

\section{PENDAHULUAN}

Dalam kehidupan manusia dari dulu sampai masa kini teknologi tidak pernah terlepas terutama dalam penggunaan barang-barang atau peralatan yang terbuat dari logam atau paduannya. Hal itu disebabkan karena logam mempunyai sifat-sifat : kuat, ulet, keras mampu menghantarkan listrik atau panas yang baik. Misalnya baja dapat dibuat untuk jembatan, bangunan, konstruksi mesin. Untuk penggunaan logam/paduannya secara tepat diperlukan pengetahuan yang cukup tentang sifat-sifat logam yang umum dipakai dan juga untuk menghindari kemungkinan-kemungkinan yang ditimbulkan oleh kesalahan dalam pemilihan bahan. Dengan berbagai cara percobaan dan penelitian diharapkan sifat-sifat logam dapat diketahui dan ditingkatkan sebaik mungkin [1]. Dalam bidang industri logam/paduannya sering dilakukan proses perlakuan panas (heat treatmen) untuk mendapatkan sifat ketangguhan, kekuatan dan sifat mekanis lainnya. Proses laku panas pada logam ada bermacam-macam diantaranya annealing, normalizing, tempering dan hardening. Untuk mendapatkan sifat ketangguhan dan kekerasan dilakukan dengan proses hardening.

Proses Hardening adalah proses pemanasan logam/baja sampai temperatur austenitisasi kemudian ditahan pada temperatur tersebut dalam waktu tertentu (holding time) kemudian didinginkan dengan pencelupan ke dalam media pendingin tertentu. Media pendingin yang dapat digunakan diantaranya : air, minyak, air garam, oli dan lain sebagainya [2]. Untuk menentukan proses pemanasannya kapan bisa dibentuk dan kapan bisa dicelupkan ke air untuk mendapatkan ketajaman belum begitu banyak orang yang mengetahui pengetahuan tentang itu. Selain sifat mekanik bahan harus diketahui juga perlu dipertimbangkan spesifikasi dari bahan yang akan digunakan [1]. Bahan yang digunakan harus didapat dengan cukup mudah dan biaya murah.

Hasil-hasil laporan ilmiah yang ada, tentang hubungan perlakuan panas dengan ketangguhan yang diteliti belum banyak ada sifatnya terbatas. Oleh karena itu maka peneliti mengambil masalah tentang pengaruh perlakuan temperatur dan media pendinginan terha dap sifat ketangguhan baja AISI 3215. Hal ini perlu dilakukan, nantinya diharapkan dapat dijadikan sebagai suatu masukan dalam menentukan perlakuan logam khususnya materialmaterial kandungan karbon rendah.

Dasar Teori yang dipakai adalah sebagai berikut:

\section{a. Perlakuan Panas (Heat Treatment)}

Proses pemanasan dan pendinginan untuk mendapatkan sifat-sifat tertentu itu pada batas kemampuannya disebut dengan perlakuan panas. Proses perlakuan panas pada dasarnya terdiri dari beberapa tahapan yaitu : pemanasan sampai temperature tertentu, penahanan beberapa saat sehingga temperaturnya merata dan pendinginan dengan kecepatan tertentu dengan media pendinginnya. Pada perlakuan ini tergantung pada sifat yang diinginkan. Proses heat treatment merupakan salah satu proses yang penting dalam pembuatan bagian-bagian mesin dan perkakas. Proses heat treatment dapat diterapkan pada baja karbon selain untuk mengeraskan baja juga dipergunakan untuk memperbaiki sifat kekerasan serta ketangguhannya [3].

\section{b. Pengerasan (Hardening)}

Pengerasan atau hardening biasanya dilakukan untuk memperoleh sifat tahan aus permukaan dan ketangguhan yang lebih baik. Proses pengerasan dilakukan dengan memanaskan baja ke daerah austenit lalu didinginkan dengan cepat melewati critical cooling ratenya atau batas kritis dari kecepatan pendinginan dengan pendinginan ini terbentuk martensit yang keras. Struktur kristal martensit berbentuk 
Body Centered Tetragonal dari awal yaitu mula-mula austenit yang didinginkan dengan cepat dan dapat mencapai temperatur $A_{1}$ tanpa terjadi perubahan struktur lain. Pada temperatur yang rendah ini austenit mengalami driving force berubah dari struktur kristal face centred cubic mencapai Body Centered cubic, sehingga menimbulkan pergeseran terhadap atom-atom. Hal ini menyebabkan atom-atomnya sedikit bergeser ke dalam bentuk Body Centered cubic tapi tidak dapat terbentuk, melainkan menjadi Body Centered Tetragonal karena salah satu rusuk sel satuannya lebih panjang dari yang lain $[4,5]$.

\section{c. Baja Karbon}

Baja merupakan paduan Besi-Karbon dengan kandungan karbon berkisar antara $0,025-2 \%$. Seperti pada diagram fase $\mathrm{Fe}_{-} \mathrm{Fe}_{3} \mathrm{C}$ terlihat bahwa batas garis larutan austenit berawal dari titik $910^{\circ} \mathrm{C}$ untuk besi murni hingga $732^{\circ} \mathrm{C}$ untuk paduan dengan kadar karbon $0,8 \%$, kemudian meningkat terus hingga $1130^{\circ} \mathrm{C}$ untuk paduan dengan kadar karbon 2\%. Baja merupakan logam yang paling banyak digunakan sebagai bahan industri. Karena lebih ekonomis dan jenisnya banyak serta sifatnya yang bervariasi tergantung dari perlakuan panas yang diberikan dan mudah didapat, sehingga akan memudahkan pemilihan sesuai dengan kebutuhan yang di inginkan [1].

\section{d. Karakteristik Baja Karbon}

Baja memiliki beberapa kombinasi sifat - sifat yang menjadikannya sebagai bahan teknik yang luas penggunaannya. Sifat-sifat penting yang menyebabkan dipilihnya baja Adalah mempunyai kekuatan statik dan kekuatan dinamik, ulet, mudah diolah, tahan korosi dan mempunyai sifat electromagnet $[2,3]$.

\section{e. Klasifikasi Baja Karbon}

Baja adalah paduan besi dan karbon dengan sedikit unsur-unsur lain seperti Si, Mn, $\mathrm{P}, \mathrm{S}$ dan $\mathrm{Cu}$. Sifat baja banyak ditentukan oleh kadar karbon nya disamping oleh paduannya. Baja dilihat dari tranformasinya ada 3 macam baja (1) Baja dengan titik transformasi $A_{1}$, berupa ferit di bawah $A_{1}$ dan austenit pada $A_{3}$ atau diatas $A_{1}$. (2) Baja dengan titik transformasi $A_{1}$ di bawah temperatur kamar, berupa austenit dibawah temperatur kamar. (3) Baja dengan daerah austenit yang kecil, berupa ferit sampai temperatur tinggi pada daerah komposisi tertentu. Baja juga juga dapat diklasifikasikan berdasarkan kadar karbonnya : (a) Baja karbon rendah dengan kandungan karbon kurang dari 0,30\%. (b) Baja karbon sedang dengan kandungan karbon $0,30 \%$ sampai dengan $0,45 \%$. (c) Baja karbon tinggi dengan kandungan karbon antara $0,45 \%$ sampai $1,70 \%$. [5] 


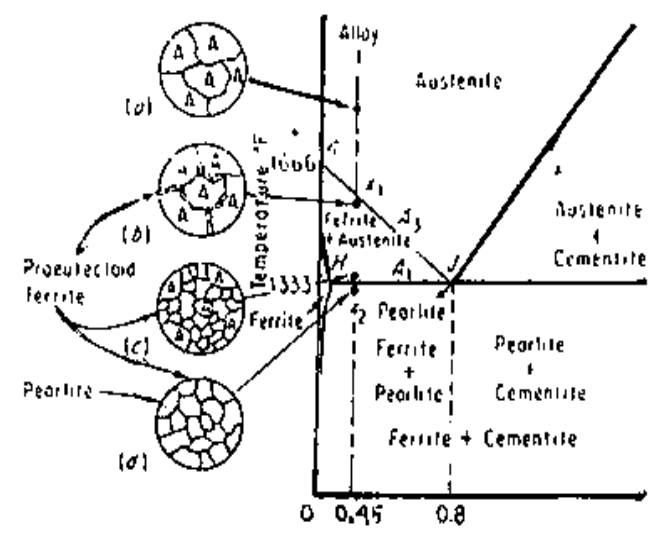

Gambar 1. Diagram $\mathrm{Fe}_{-} \mathrm{Fe}_{3} \mathrm{C}$ baja karbon

\section{f. Laju Pendinginan}

Untuk dapat memperoleh struktur yang sepenuhnya martensit maka laju pendinginan harus dapat mencapai laju pendinginan kritis (critical cooling rate). Dengan laju pendinginan yang kurang dari laju pendinginan kritis akan mengakibatkan adanya sebagian austenit yang tidak bertransformasi menjadi martensit tetapi menjadi struktur lain, sehingga kekerasan maksimum tentu tidak akan tercapai. Laju pendinginan yang terjadi pada suatu benda kerja tergantung pada beberapa faktor, terutama : Jenis media pendinginnya, temperatur media pendingin dan kuatnya sirkulasi pada media pendingin [6].

\section{g. Temperatur Austenitisasi}

Pada proses pengerasan, pemanasan harus dilakukan sampai temperatur austenitisasi, sehingga tercapai struktur austenit karena hanya austenit yang dapat bertransformasi menjadi martensit. Bila pada saat pemanasan masih terdapat struktur lain selain austenit, seperti ferrit yang lunak atau karbida belum seluruh karbon larut dalam austenit. Dimana kekerasan martensit sangat tergantung pada kadar karbon dalam austenit. Pada baja karbon, temperatur austenitisasi untuk baja hypoutektoid biasanya berkisar antara 30 sampai $50^{\circ} \mathrm{C}$ di atas temperatur kritis $\mathrm{A}_{3}$ dan 30 sampai $50^{\circ} \mathrm{C}$ di atas temperatur kritis $\mathrm{A}_{1}$ untuk baja hypereutectoid [4].

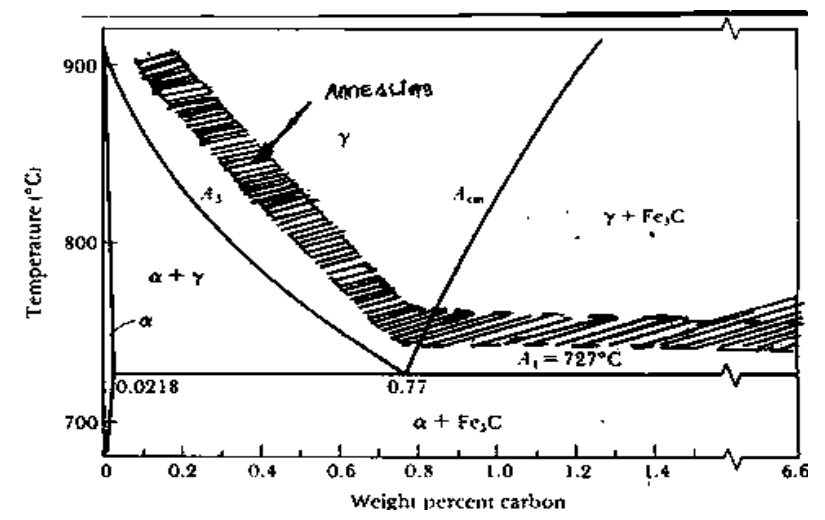

Gambar 2. Hubungan antara temperatur austenitisasi baja dengan kadar karbon 


\section{h. Media Pendinginan}

Setelah proses pemanasan dan holding time, untuk mendapatkan struktur martensit maka austenit yang terjadi hanya didinginkan dengan cepat. Setidaknya dapat mencapai laju pendinginan kritis. Ada beberapa media pendingin yang sering digunakan dalam proses pengerasan, antara lain campuran air, minyak, udara dan air garam. Media pendingin air adalah pendinginan yang paling tua dan mudah didapatkan serta mempunyai kemampuan pendinginan yang tinggi sekali, maka dari itu air biasanya digunakan untuk pendinginan dari baja yang tidak terlalu tinggi, seperti baja karbon. Kekurangan pendingian air adalah laju pendinginan sangat tinggi pada daerah pembentukan martensit sehingga akan menyebabkan terjadinya tegangan sisa akibat transformasi dan selisih temperatur. Ini akan mendorong terjadinya keretakan pada saat quenching [6].

\section{METODE}

\subsection{Prosedur Penelitian dan Persiapan Bahan}

Bahan yang digunakan pada penelitian ini adalah baja 3215 yang termasuk baja karbon menengah dengan komposisi sebagai berikut $: \mathrm{C}=0,44 \%, \mathrm{Si}=0,25 \%, \mathrm{Mn}=0,7 \%$. Media Pendingin yang digunakan dalam penelitian ini adalah : air tawar, air Garam (air laut) dan minyak (minyak nabati).

\subsection{Alat-alat Penelitian}

1. Dapur pemanas, untuk memanaskan spesimen sampai temperatur yang diinginkan.

2. Mesin poslishing, menghaluskan bagian permukaan benda uji.

3. Alat uji ketangguhan

4. Tempat media pendingin

5. Amplas dengan grade tertentu.

Pengujian impact yang dilakukan dengan mesin uji impact

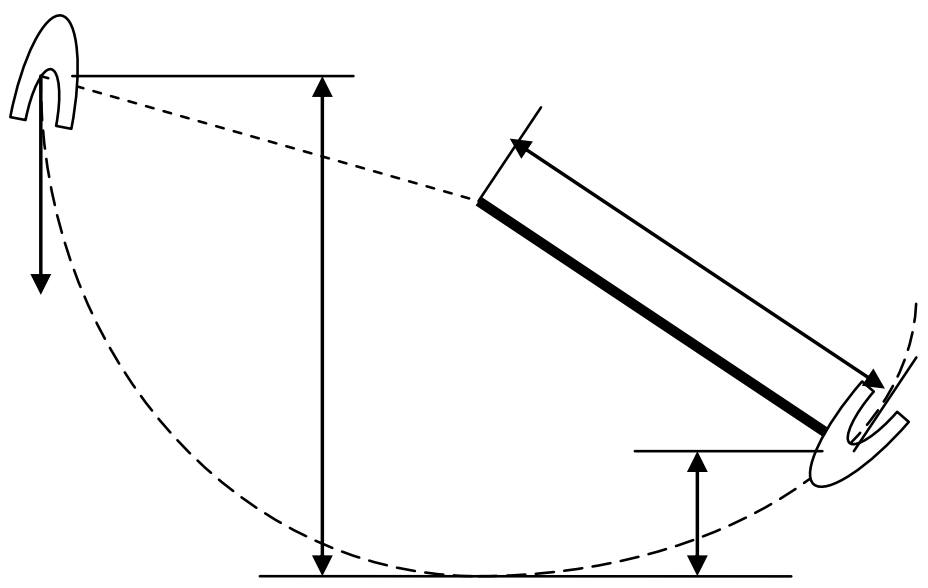

$\mathrm{W}=$ berat dari pendulum $(\mathrm{kgf})=\mathrm{m} \cdot \mathrm{g}$

$\mathrm{m}=\operatorname{massa}(\mathrm{kgm})$

$\mathrm{g}=\operatorname{gravitasi}\left(\mathrm{m} / \mathrm{det}^{2}\right)$

$\mathrm{h}=$ tinggi awal $(\mathrm{m})$

$\mathrm{h}_{1}=$ tinggi akhir $(\mathrm{m})$

= sudut awal

$=$ sudut akhir

ISO U notch test pieces

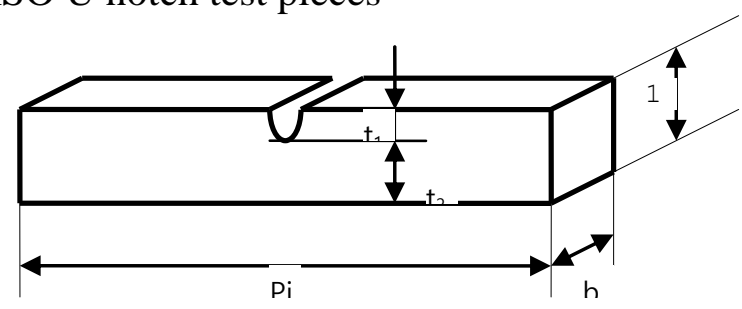

Gambar 3. Skema Uji Impack dan Bentuk specimen uji metode Charpy [7] 
Jumlah penyediaan benda uji dan bahan benda uji untuk tiap-tiap tipe benda uji disesuaikan dengan kebutuhan. Untuk data yang didapat dari pengujian diolah dengan menggunakan persamaan :

$$
A_{k}=A k_{b a g}-A_{R}
$$

dengan :

$A_{k}$

$\mathrm{A} \mathrm{k}_{\mathrm{bag}} \quad=$ Energi yang dicatat ditunjukkan oleh jarum penunjuk $(\mathrm{Nm})$

$\mathrm{A}_{\mathrm{R}} \quad=$ Energi gesekan total yang hilang.

Kemudian dicari kekuatan impact material (ak) yang ditest dengan rumus :

Ak

ak

So

dengan :

So = luas awal didaerah yang ada takikan $\left(\mathrm{cm}^{2}\right)$

\subsection{Prosedur Penelitian}

1. Pesiapan material baja pegas daun, dipotong sesuai dengan ukuran yang ditentukan.

2. Spesimen yang sudah dibentuk, kemudian dimasukkan ke dalam Dapur pemanas.

3. Pada Dapur pemanas dapat diatur temperatur dari $800^{\circ} \mathrm{C}, 850^{\circ} \mathrm{C}$, dan $900^{\circ} \mathrm{C}$ dengan masing-masing diholding time 15 menit

4. Material dikeluarkan dari dapur pemanas dan didinginkan dengan media pendingin masing-masing : air tawar, air laut dan minyak. Benda uji dibersihkan dengan polisher dan selanjutnya dijepit pada alat uji.

5. Spesimen di seting pada mesin uji impact dan dilakukan pengujian

6. Dilakukan dengan pemberian beban .

7. Beban diangkat dan pembacaan data yang diperoleh

8. Data nilai ketangguhan dapat dibaca dan dicatat dari mesin uji.

9. Pengujian selesai.

\section{HASIL DAN PEMBAHASAN}

3.1 Pengaruh Temperatur terhadap Ketangguhan bahan baja AISI 3215.

Data hasil penelitian dapat dilihat pada tabel 1

Tabel 1 Pengaruh perlakuan media pendingin dan temperature pemanasan

\begin{tabular}{cccc}
\hline \multirow{2}{*}{$\begin{array}{c}\text { PERLAKUAN } \\
\text { PANAS }\end{array}$} & \multicolumn{3}{c}{ MEDIA PENDINGINAN } \\
\cline { 2 - 4 } & MINYAK & AIR LAUT & AIR TAWAR \\
\hline & 331,250 & 342,500 & 355,000 \\
\cline { 2 - 4 } & 343,750 & 352,500 & 348,750 \\
\cline { 2 - 4 } Rata-rata & 340,000 & 350,000 & 365,000 \\
& $\mathbf{3 3 8 , 3 3 3}$ & $\mathbf{3 4 8 , 3 3 3}$ & $\mathbf{3 5 6 , 2 5 0}$ \\
\hline & 371,850 & 392,500 & 383,750 \\
\cline { 2 - 4 } & 385,000 & 372,500 & 395,000 \\
\hline Rata-rata & 365,000 & 387,500 & 393,750 \\
\hline & $\mathbf{3 7 3 , 9 5 0}$ & $\mathbf{3 8 9 , 1 6 7}$ & $\mathbf{3 9 0 , 8 3 3}$ \\
\cline { 2 - 4 } & 392,500 & 405,000 & 421,870 \\
\cline { 2 - 4 } & 406,250 & 410,000 & 409,370 \\
& &
\end{tabular}


Jurnal METTEK Volume 4 No 1 (2018) pp 23 - 30

ojs.unud.ac.id/index.php/mettek

\begin{tabular}{cccc} 
& 408,750 & 396,870 & 395,000 \\
\cline { 2 - 4 } Rata-rata & $\mathbf{4 0 2 , 5 0 0}$ & $\mathbf{4 0 3 , 9 5 7}$ & $\mathbf{4 0 8 , 7 4 7}$ \\
\hline
\end{tabular}

Grafik hasil penelitian pengaruh temperatur dapat dilihat pada gambar 4.

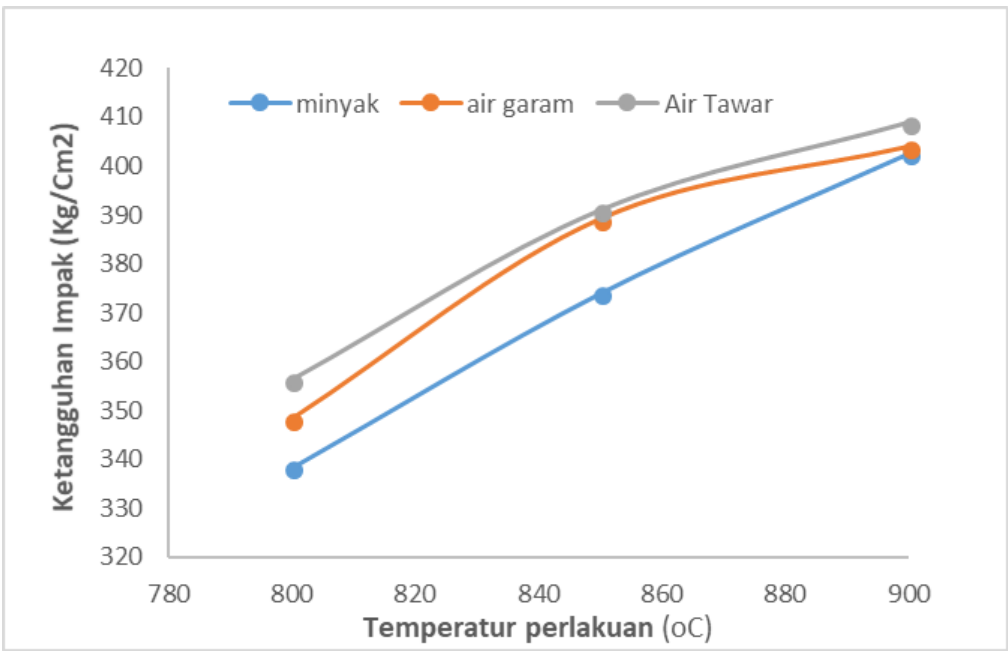

Gambar 4. Grafik hubungan Temperatur perlakuan terhadap Ketangguhan impak

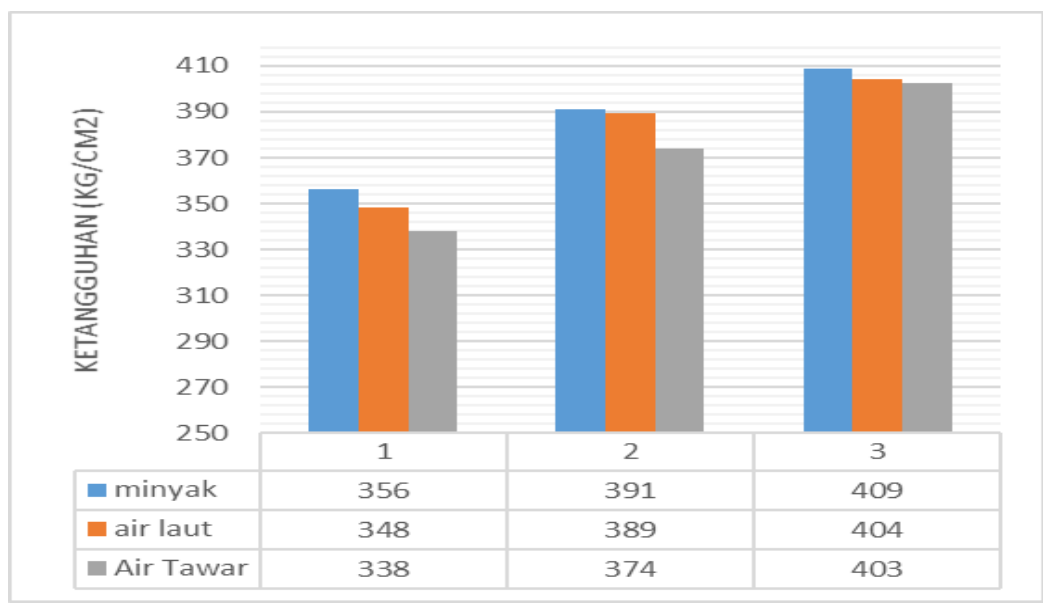

Gambar 5. Grafik hubungan media pendinginan terhadap Ketangguhan impak.

Dari gambar 4 secara grafik terlihat bahwa ada peningkatan ketangguhan impack dari setiap peningkatan temperature perlakuan mulai dari temperature $800^{\circ} \mathrm{C}, 850^{\circ} \mathrm{C}$ dan $900^{\circ} \mathrm{C}$. Pada temperatur $800^{\circ} \mathrm{C}$ dan media pendingin minyak memberikan nilai ketangguhan impack rata-rata $338,333 \mathrm{~kg} / \mathrm{Cm}^{2}$, dengan media air laut memberikan nilai ketangguhan impack rata-rata $348,333 \mathrm{~kg} / \mathrm{Cm}^{2}$, dan dengan media pendingin air tawar memberikan nilai ketangguhan rata-rata $356,250 \mathrm{~kg} / \mathrm{Cm}^{2}$. Pada temperatur $850^{\circ} \mathrm{C}$ dan media pendingin minyak memberikan nilai ketangguhan impack rata-rata $338,333 \mathrm{~kg} / \mathrm{Cm}^{2}$, dengan media air laut memberikan nilai ketangguhan impack rata-rata $389,167 \mathrm{~kg} / \mathrm{Cm}^{2}$, dan dengan media pendingin Air Tawar memberikan nilai ketangguhan rata-rata $390,833 \mathrm{~kg} / \mathrm{Cm}^{2}$.. Pada temperature $900^{\circ} \mathrm{C}$ dan media pendingin minyak memberikan nilai ketangguhan impack ratarata $402,500 \mathrm{~kg} / \mathrm{Cm}^{2}$, dengan media air laut memberikan nilai ketangguhan impack rata-rata $403,957 \mathrm{~kg} / \mathrm{Cm}^{2}$, dan dengan media pendingin air tawar memberikan nilai ketangguhan rata-rata $408,747 \mathrm{~kg} / \mathrm{Cm}^{2}$. 
Ketangguhan meningkat dengan meningkatnya temperatur dari rata-rata 348,333 $\mathrm{kg} / \mathrm{Cm}^{2}$ (temperatur $850^{\circ} \mathrm{C}$ ) menjadi rata-rata $408,747 \mathrm{~kg} / \mathrm{Cm}^{2}$ (temperatur $900^{\circ} \mathrm{C}$, pendinginan air tawar). Pada gambar 6 terlihat adanya pengaruh media pendingin minyak, air laut dan air tawar. Hal ini disebabkan dengan meningkatnya temperatur yang dipengaruhi oleh jenis media pendingin dimana media pendingin masing mempunyai kecepatan pendinginan yang berbeda. Dalam penelitian ini dengan media pendinginan yang mempunyai laju pendinginan cepat (air tawar) memberikan pengaruh terhadap ketangguhan karena terbentuknya martensit dengan struktur yang keras. Kekerasan yang tinggi pada suatu material akan memberikan pengaruh terhadap ketangguhan impeck. Semakin getas material maka ketangguhan yang dimiliki oleh material menurun. Sifat mekanis ketangguhan adalah kemampuan material untuk menyerap energi sesaat sebelum terjadi fraktur pada struktur itu [6]. Pada benda uji statis (material yang diberikan pengujian dengan beban impack) mempunyai patahan yang berbeda dengan benda uji dinamis, dimana pada benda uji dinamis permukaan patah terdapat alur retak dan bidang patahannya tampak lebih kasar atau berserabut (fibrous) [7]. Sedangkan pada pengujian impack adanya kontur patahan merata untuk material getas dan ada berserabut untuk material ulet.

\section{SIMPULAN}

Ketangguhan yang terjadi pada proses temperatur dan media pendinginan pada material baja AISI 3215 memperlihatkan bahwa ada pengaruh dengan meningkatnya temperatur secara nyata, dari gambar 4 jelas terlihat.

Media pendinginan memberi pengaruh terhadap ketangguhan baja AISI 3215 yang ditunjukkan terjadi peningkatan ketangguhan dari terendah pada temperatur $800^{\circ} \mathrm{C}$ media pendinginan minyak $\left(33,833 \mathrm{~kg} / \mathrm{cm}^{2}\right)$ sampai temperatur $900^{\circ} \mathrm{C}$ media air tawar dengan ketangguhan $\left(40,8747 \mathrm{~kg} / \mathrm{cm}^{2}\right)$.

\section{UCAPAN TERIMA KASIH}

Terimakasih yang dalam dan tak ternilai saya berikan Kepada Laboratorium Metalurgi Teknik Mesin Fakultas Teknik Universitas Udayana dan Kepala Laboratorium Produksi Teknik Mesin Unud, sebagai tempat melaksanakan penelitian ini.

\section{DAFTAR PUSTAKA}

[1]. Dieter George E, Alih Bahasa Sriati Djapri, 1992, Metalurgi Mekanik, Edisi Ketiga, Jilid III, Erlangga, Jakarta.

[2] Askeland Donald R, 1984, The Science and Engineering of Material, University of Missouri-Rolla.

[3] Avner Sidney H, 1987, Introduction to Physical Metallurgy, Second Edition, Mc GrawHill International Book Company, Tokyo.

[4] Karl E. Thelning, 1984, Steel and Its Heat Treatment, Second Edtion, Butterworths, London.

[5] Prabhudev K.H, 1988, Hand Book of Heat Treatment of Steel, Mc Graw-Hill Publishing Company Limited, New Delhi

[6] Surdia Tata, Shinroku, 1999, Pengetahuan Bahan Teknik, Penerbit Pradnya Paramita, Jakarta.

[7] Suherman Wahid, 1988, Ilmu Logam II, Penerbit Jurusan Teknik Mesin FTI-ITS, Surabaya.

[8] Budiman Anton, Niemann G, 1992, Elemen Mesin, Edisi II, Jilid I, PT Gelora Aksara Pratama, Jakarta. 